\title{
Reduction in Cerebral Ischemic Injury in the Newborn Rat by Potentiation of Endogenous Adenosine
}

\author{
JEFFREY M. GIDDAY, JILL C. FITZGIBBONS, AARTI R. SHAH, MICHAEL J. KRAUJALIS, AND \\ T. S. PARK
}

Departments of Neurosurgery, Cell Biology and Physiology, and St. Louis Children's Hospital, Washington University School of Medicine, St. Louis, Missouri 63110

\begin{abstract}
Because of ontogenic influences on the pathophysiologic mechanisms of brain injury in the perinatal brain, and in particular, the incomplete development of adenosine receptor systems, we investigated the potential for adenosine to provide cerebroprotection in a well established newborn rat model of hypoxiaischemia. Fifteen litters of postnatal $d 7$ animals were subjected to unilateral carotid ligation and exposure to hypoxia (8\% oxygen) for $3 \mathrm{~h}$. Immediately after hypoxia-ischemia, animals received either the adenosine deaminase inhibitor deoxycoformycin (DCF; $2.5 \mathrm{mg} / \mathrm{kg}$ intraperitoneally) or the adenosine uptake inhibitor propentofylline (PPF; $10 \mathrm{mg} / \mathrm{kg}$ intraperitoneally); paired littermates received an equivalent volume of normal saline. On postnatal d 14, injury or protection was assessed by differences in hemispheric weights, morphometric determinations of infarct area, and histopathologic analyses. DCF resulted in a $34 \%(p=0.02)$ and $31 \%(p=0.03)$ reduction in hemispheric weight disparities and infarct area, respectively; for PPF, these reductions were $46 \%(p=0.03)$ and $32 \%(p=0.04)$,
\end{abstract}

ABSTRACT
Although the brain of the newborn exhibits a higher tolerance to ischemia than that of the adult, morbidity and mortality from hypoxic-ischemic encephalopathy in the perinatal period remain high (1). Although the general pathophysiologic mechanisms underlying cerebral ischemic injury are probably similar between age groups, the unique characteristics of energy and glucose metabolism (2), glutamate receptor physiology (3, $4)$, and vascular regulation $(5,6)$ in the newborn brain may dictate separate therapeutic regimens for affected neonates relative to adults.

In recent years, experimental evidence has accumulated from adult animal models attesting to the neuroprotective properties of the purine nucleoside adenosine in the setting of

Received Fcbruary 3, 1995; accepted April 6, 1995

Correspondence and reprint requests: Jeffrey M. Gidday, Ph.D., Department of Neurosurgery, St. Louis Children's Hospital, St. Louis, MO 63110.

Supported by the Center for the Study of Nervous System Injury at Washington University. respectively. Light microscopic examinations of striatum, thalamus, hippocampus, and cortex revealed that both drugs significantiy improved histologic scores as well. Measurements in six separate litters indicated that neither drug significantly reduced core body temperature for at least $6 \mathrm{~h}$ postadministration. These findings indicate that potentiation of endogenous adenosine levels in the perinatal brain can significantly ameliorate brain injury. Each of these treatment strategies was effective even when administered after the hypoxic-ischemic insult. Thus, further investigations of adenosinergic therapies are warranted in this and other perinatal models of cerebral ischemia to elucidate in detail their potential for clinical application. (Pediatr Res 38: 306-311, 1995)

\author{
DCF, deoxycoformycin \\ PPF, propentofylline \\ NMDA, $N$-methyl-D-aspartate
}

cerebral ischemia (see Ref. 7 for review), and the mechanistic basis for such an adenosine-mediated reduction in ischemic brain injury has been outlined (8). Ontogenic studies of the brains of fetal and newborn animals indicate that the requisite metabolic enzymes and transporters for adenosine are fully matured at birth or earlier $(9-12)$. There is also consistent evidence that cerebral adenosine production increases in response to perinatal hypoxia-ischemia (13-16). Although cerebral vessels in fetal and newborn animals exhibit the characteristic vasodilatative response to adenosine $(17,18)$, significant development of neuronal adenosine receptors, particularly in terms of density and coupling to second messengers, may occur postnatally $(12,19,20)$. Thus, adenosinebased treatments may not provide therapeutic efficacy against cerebral hypoxia-ischemia in the perinatal period. To address this possibility, we used two different drugs to determine whether potentiating endogenous adenosine would confer cerebroprotection in a neonatal model of hypoxia-ischemia. 


\section{METHODS}

Experimental model. The well characterized Rice-Vannucci model of perinatal hypoxia-ischemia was used (21), wherein unilateral brain injury is induced by a combination of unilateral carotid ligation and exposure to hypoxia. Briefly, 15 litters of postnatal $\mathrm{d} 7$ Sprague-Dawley rat pups were anesthetized with halothane, and their left carotid artery was ligated, cauterized, and cut to ensure permanent blood flow interruption; incisions were closed with cyanoacrylate. The entire surgical procedure was typically completed in less than 5 min. Pups were allowed to recover in a warm environment for 15 min before their return to the dam. Ninety minutes after ligating the carotid of the last littermate, the pups were exposed to $3 \mathrm{~h}$ of normothermic hypoxia ( $8 \%$ oxygen). Six interconnected Plexiglas chambers $\left(440 \mathrm{~mL}^{3}\right)$ submerged in water warmed to $36.0^{\circ} \mathrm{C}$ were used; each chamber held either one or two animals, and received prewarmed hypoxic gas at $100 \mathrm{~mm}^{3} / \mathrm{min}$.

Drug treatments. Within 5-10 min of return to normoxia, half the pups of each litter received a single dose of either DCF (pentostatin; $2.5 \mathrm{mg} / \mathrm{kg}$ intraperitoneally; Parke-Davis, Ann Arbor, MI), which inhibits brain adenosine deaminase (22), or PPF (HWA 285; $10 \mathrm{mg} / \mathrm{kg}$ intraperitoneally; Hoechst, Wiesbaden, Germany), which inhibits reuptake of extracellular adenosine (23). The animals were then returned to the dam and monitored for 30-60 min to be sure that no pup was left untended by the dam. Pups were reared under normal conditions until postnatal $\mathrm{d} 14$, when injury analyses were undertaken. Seven pups from the 8 DCF litters and 12 pups from the 7 PPF litters were used as nonligated, nonhypoxic controls, and were also killed at postnatal d 14 .

In six separate litters, we assessed the protective effects of MK-801, the noncompetitive NMDA receptor antagonist. As in the DCF- and PPF-treated animals, MK-801 (3 mg/kg, intraperitoneally) was administered as a single dose immediately after the hypoxic period was terminated. Hemispheric weight analyses were performed 1 wk later.

In another six litters, rectal temperatures were obtained under baseline conditions and at $0.5,1,2,4$, and $6 \mathrm{~h}$ after intraperitoneal administration of DCF or PPF to determine whether these compounds caused a significant hypothermia. In these studies, each litter was divided equally, with half receiving either DCF or PPF, and half receiving saline vehicle. Animals were returned to the dam after the injections and removed thereafter as necessary for the rapid assessment of core body temperature.

Quantification of injury or neuroprotection. Injury was assessed by criteria previously established for this model (24, 25), which included a combination of hemispheric weight measurements, determinations of infarct area, and histopathologic analyses. In brief, postnatal d 14 animals were killed by decapitation secondary to halothane overdose, and their brains were removed and placed in chilled saline. The cerebellum was removed, as well as the olfactory lobes; the forebrain was then sectioned at the midline; left and right hemispheric weights to the nearest $0.1 \mathrm{mg}$ were obtained. The hemispheres were then realigned and frozen together on aluminum foil in contact with a sheet of dry ice. Ten-micron thick coronal sections were obtained and Nissl-stained (methylene blue/azure II).

In the majority of animals from the DCF experiments, and in more than half the animals from the PPF experiments, relative infarct area was determined by bilateral morphometric analyses of hemispheric cross-sectional area in coronal sections from two different anteroposterior levels (the dorsal hippocampus and the striatum) using an image analysis system (Optimas; Bioscan, Inc., Edmonds, WA). Infarct area was measured in at least three consecutive coronal sections for each level, and the average change in infarct area at these two anteroposterior levels is reported herein. Alterations in neuronal morphology were assessed by light microscopy at $40 \times$ in three adjacent coronal sections. Neurons in the caudate putamen and neurons in the lateral cortex were examined at the level of the striatum (anterior). Hippocampal subfields, and neurons of the medial, lateral, and ventral thalamus were examined at the level of the dorsal hippocampus (posterior). The extent of alterations in neuronal morphology, ranging from pyknotic nuclei to necrosis to frank infarction, was scored for each region by a blind observer using the following 5-point semiquantitative scale: 0 $\equiv$ no neurons injured; $1 \equiv$ mild injury; $2 \equiv$ moderate injury with some necrotic neurons; $3 \equiv$ severe injury with widespread necrosis; $4 \equiv$ complete infarction. Cerebral hypoxicischemic injury in the MK-801-treated litters was assessed only by hemispheric weight comparisons.

Statistical analyses. All data are shown as mean \pm SEM. Comparisons of hemispheric weights, infarct areas, and rectal temperatures between drug-treated and vehicle-treated groups were by unpaired $t$ tests. The nonparametric Mann-Whitney test was used to determine significance for the regional and composite histopathologic scores. Linear regression was performed to determine the extent of correlation between reduction in hemispheric weight and reduction in infarct volume. A $p$ value less than 0.05 was considered significant.

\section{RESULTS}

DCF-treated animals. Animals that received the adenosine deaminase inhibitor DCF after hypoxia-ischemia exhibited significantly less brain injury relative to vehicle-treated littermates. In the eight litters used to assess the cerebroprotective effects of DCF, the 25 vehicle-treated animals showed a $29 \pm$ $3 \%$ reduction in hemispheric weights, whereas only a $19 \pm 3 \%$ reduction in hemispheric weights was noted in the $26 \mathrm{DCF}$ treated animals (Fig. 1). By this criterion, a $34 \%$ reduction in injury ( $p=0.02$ ) was achieved by DCF. In the 20 vehicletreated and 22 DCF-treated animals from the above groups that were used for morphometric analyses, $29 \pm 3 \%$ and $20 \pm 3 \%$ reductions in hemispheric area ipsilateral to the carotid ligation were measured, respectively, reflecting a $31 \%$ reduction $(p=$ 0.03 ) in infarct area by DCF. These changes in infarct area were highly correlated $(r=0.89 ; p<0.001)$ to the changes in hemispheric weights measured in these same brains (Fig. 2). DCF treatment did not cause hypothermia (Table 1).

Regional histopathologic analyses indicated that DCF reduced the severity of neuronal injury across several regions (Table 2). Significant improvements in neuronal injury scores 


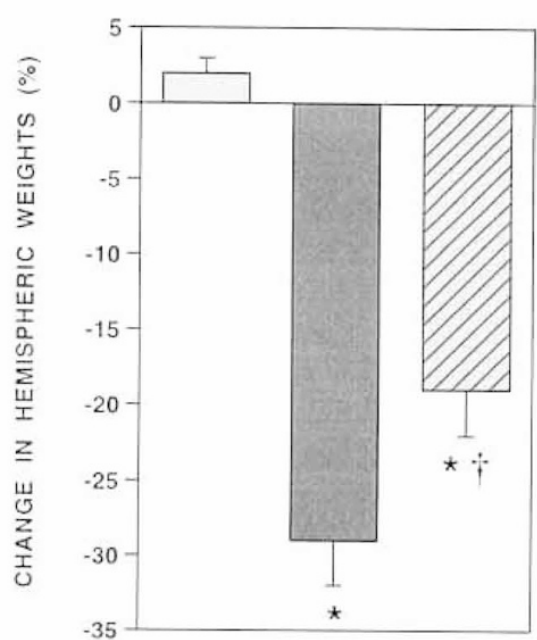

Figure 1. Cerebroprotection by DCF as cvidenced by hemispheric weight disparities. The reduction in hemispheric weight in DCF-treated $(n=27$; harched bar) was $34 \%$ less $(p=0.02)$ than that measured in vehicle-treated littermates ( $n=25$; shaded bar). Weight changes in nonligated and nonhypoxic controls $\left(n=7\right.$; open bar) are shown. $\left({ }^{*} p<0.05\right.$ vs nonligated, nonhypoxic controls; $\nmid p<0.05$ vs vehicle-treated animals).

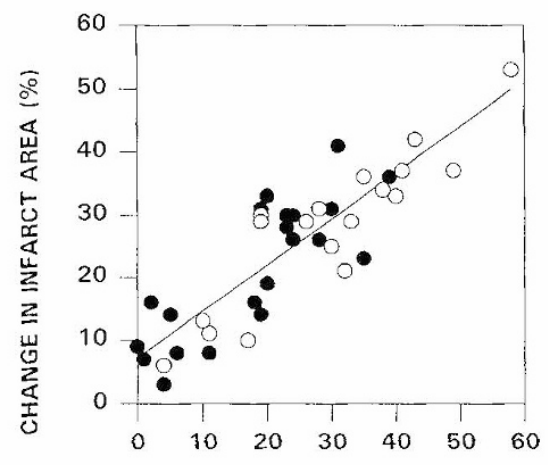

CHANGE IN HEMISPHERIC WEIGHT (\%)

Figure 2. Significant correlation $(r=0.89 ; p<0.001)$ between the reduction in ipsilateral hemispheric weight and morphometrically determincd reduction in ipsilateral hemispheric arca in vehicle-treated $(n=20$; open circles) and DCF-treated ( $n=22$; filled circles) animals. The equation describing the regression line is $y=0.76 x+6.3$.

were evidenced in thalamus and cortex, and in the CA1 hippocampal subfield. There was a strong trend for improvement in striatal histopathologic scores as well. Figure 3 shows the composite distribution of histopathologic injury scores for all measured regions in the DCF- and vehicle-treated animals; the composite injury score for DCF-treated animals (1.49 $0.11)$ was significantly lower $(p<0.0001)$ than that measured in vehicle-treated littermates $(2.39 \pm 0.12)$.

PPF-treated animals. The adenosine uptake blocker PPF also exhibited cerebroprotective actions in this model. From 7 litters, a $26 \pm 4 \%$ decrease in hemispheric weight was evidenced in vehicle-treated animals $(n=26)$, whereas in the PPF-treated animals $(n=27)$, the decrease was only $14 \pm 3 \%$; thus, based on weight disparities, postischemic administration of PPF reduced brain injury by $46 \%$ ( $p=0.03$; Fig. 4). Morphometric analyses revealed a $34 \pm 4 \%$ decrease in hemispheric area in vehicle-treated animals $(n=13)$, whereas a
$32 \%(p=0.04)$ reduction in infarct area (to $23 \pm 4 \%)$ was afforded by PPF $(n=14)$. As in the DCF experiments, changes in infarct area were highly correlated $(r=0.87 ; p<0.001$; regression distribution not shown) to changes in hemispheric weights. As with DCF, no evidence of PPF-induced reductions in body temperature were observed for $6 \mathrm{~h}$ after drug administration (Table 1).

A reduction in regional histologic injury scores with PPF was realized only in the striatum, which is likely the result of having considerably fewer brains $(n=27)$ available for analysis relative to the DCF-treated animals (Table 3 ). However, the composite histopathologic injury score for PPF-treated animals $(2.49 \pm 0.16)$ was significantly lower $(p=0.016)$ than that measured in vehicle-treated animals $(3.07 \pm 0.14)$; the composite distribution for these animal groups is not shown.

MK-801-treated animals. Hemispheric weight analyses revealed that MK-801 reduced brain injury by $41 \%(p=0.01)$. Vehicle-treated animals in these litters $(n=27)$ exhibited a 29 $\pm 4 \%$ reduction in hemispheric weight ipsilateral to the carotid ligation, whereas in MK-801-treated animals $(n=26)$ only showed a $17 \pm 3 \%$ reduction in hemispheric weight.

\section{DISCUSSION}

The results of the present study in perinatal rats indicate that drugs that potentiate endogenous cerebral extracellular adenosine levels can provide significant protection from hypoxicischemic injury. This protection was achieved when the animals were treated after the hypoxic-ischemic insult, was equivilent to that observed with the NMDA antagonist MK801 , and was realized in the absence of a reduction in body temperature. Such findings are in accord with adenosine's neuroprotective effects in various adult animal models of cerebral ischemia (7), and indicate that, despite incomplete maturation of adenosine receptor function $(12,19,20,26)$, the mechanisms that underlie hypoxic-ischemic brain injury in this model are amenable to adenosinergic intervention.

Adenosine exhibits many actions that would be of predicted benefit in the setting of cerebral hypoxia-ischemia. Adenosine has a depressant effect on neuronal activity as a result of several distinct functions: In vitro (27) and in vivo (28) evidence attests to its ability to inhibit stimulation-induced presynaptic release of glutamate, an important mediator of cerebral ischemic injury (29). A similar effect of adenosine on ischemia-induced dopamine release (30) may also lessen ischemic injury (31). Secondary to inducing a hyperpolarizing outward potassium current (32), adenosine helps maintain the voltage-dependent block of NMDA receptors and thereby reduces NMDA receptor-mediated calcium influx. Preliminary evidence also suggests that adenosine reduces NMDA receptor-mediated nitric oxide production (33), the result of which may also be neuroprotective (34). Adenosine is also a potent vasodilator in the perinatal brain (35), and can prevent platelet aggregation (36). With the resultant increase in perfusion, delivery of oxygen and glucose to the tissue is enhanced. An augmented availability of metabolic substrates also results from adenosine's stimulation of astrocytic glycogenolysis (37) and neuronal glucose uptake (38). Finally, in vitro studies 
Table 1. Rectal temperatures following intraperitoneal administration of DCF or PPF in comparison with saline-treated littermates and respective baselines in three litters

\begin{tabular}{|c|c|c|c|c|c|c|}
\hline \multirow[b]{2}{*}{ Treatment } & \multirow[b]{2}{*}{ Baseline } & \multicolumn{5}{|c|}{ Time after drug administration (h) } \\
\hline & & 0.5 & 1 & 2 & 4 & 6 \\
\hline Saline & $\begin{array}{r}34.8 \pm 0.2 \\
(n=16)\end{array}$ & $\begin{array}{r}35.7 \pm 0.7^{*} \\
(n=16)\end{array}$ & $\begin{array}{r}34.9 \pm 0.3 \\
(n=16)\end{array}$ & $\begin{array}{r}35.6 \pm 0.3^{*} \\
\quad(n=16)\end{array}$ & $\begin{array}{r}36.6 \pm 0.2^{*} \\
\quad(n=16)\end{array}$ & $\begin{array}{r}37.3 \pm 0.3^{*} \\
(n=15)\end{array}$ \\
\hline DCF & $\begin{array}{r}35.0 \pm 0.2 \\
(n=17)\end{array}$ & $\begin{array}{r}35.8 \pm 0.3^{*} \\
\quad(n=17)\end{array}$ & $\begin{array}{r}35.2 \pm 0.3 \\
(n=17)\end{array}$ & $\begin{array}{r}35.9 \pm 0.3^{*} \\
(n=17)\end{array}$ & $\begin{array}{r}36.4 \pm 0.2^{*} \\
(n=17)\end{array}$ & $\begin{array}{r}37.5 \pm 0.2 * \\
(n=17)\end{array}$ \\
\hline Saline & $\begin{array}{r}33.1 \pm 0.4 \\
(n=14)\end{array}$ & $\begin{array}{r}34.1 \pm 0.5^{*} \\
\quad(n=14)\end{array}$ & $\begin{array}{r}34.5 \pm 0.2^{*} \\
(n=8)\end{array}$ & $\begin{array}{r}33.6 \pm 1.0 \\
(n=14)\end{array}$ & $\begin{array}{r}34.1 \pm 1.0 \\
(n=14)\end{array}$ & $\begin{array}{r}33.5 \pm 0.9 \\
\quad(n=14)\end{array}$ \\
\hline $\mathrm{PPF}$ & $\begin{array}{r}33.8 \pm 0.4 \\
(n=14)\end{array}$ & $\begin{array}{r}34.0 \pm 0.3 \\
\quad(n=14)\end{array}$ & $\begin{array}{r}35.1 \pm 0.3^{*} \\
(n=8)\end{array}$ & $\begin{array}{r}33.8 \pm 0.9 \\
(n=14)\end{array}$ & $\begin{array}{r}34.0 \pm 0.9 \\
(n=14)\end{array}$ & $\begin{array}{r}34.2 \pm 0.8 \\
(n=13)\end{array}$ \\
\hline
\end{tabular}

$* p<0.05$ vs baseline (paired $t$ test).

$\dagger p<0.05$ vs respective saline-treated group (unpaired $t$ test).

Table 2. Summary of regional histopathologic results for vehicleand DCF-treated animals using a 5-point injury scale (from $0 \equiv$ no injury to 4 = total infarction)

\begin{tabular}{llll}
\hline \multicolumn{1}{c}{ Region $^{a}$} & $\begin{array}{c}\text { Vehicle } \\
(n=21)\end{array}$ & $\begin{array}{c}\text { DCF } \\
(n=21)\end{array}$ & $p$ value \\
\hline Striatum & $1.9 \pm 0.3$ & $1.0 \pm 0.2$ & 0.058 \\
HPCS-dentate & $1.8 \pm 0.3$ & $1.2 \pm 0.2$ & 0.274 \\
HPCS-CA1 & $3.1 \pm 0.3$ & $1.7 \pm 0.4^{* *}$ & 0.006 \\
HPCS-CA3 & $2.6 \pm 0.3$ & $2.1 \pm 0.3$ & 0.320 \\
HPCS-CA4 & $2.1 \pm 0.3$ & $1.4 \pm 0.2$ & 0.113 \\
Thalamus & $2.6 \pm 0.3$ & $1.5 \pm 0.3^{*}$ & 0.014 \\
Cortex & $2.7 \pm 0.4$ & $1.4 \pm 0.3^{* *}$ & 0.001 \\
\hline
\end{tabular}

${ }^{a} \mathrm{HPCS}$, hippocampus.

$* p<0.05$.

$* * p<0.01$ vs vehicle-treated littermates (Mann-Whitney test).

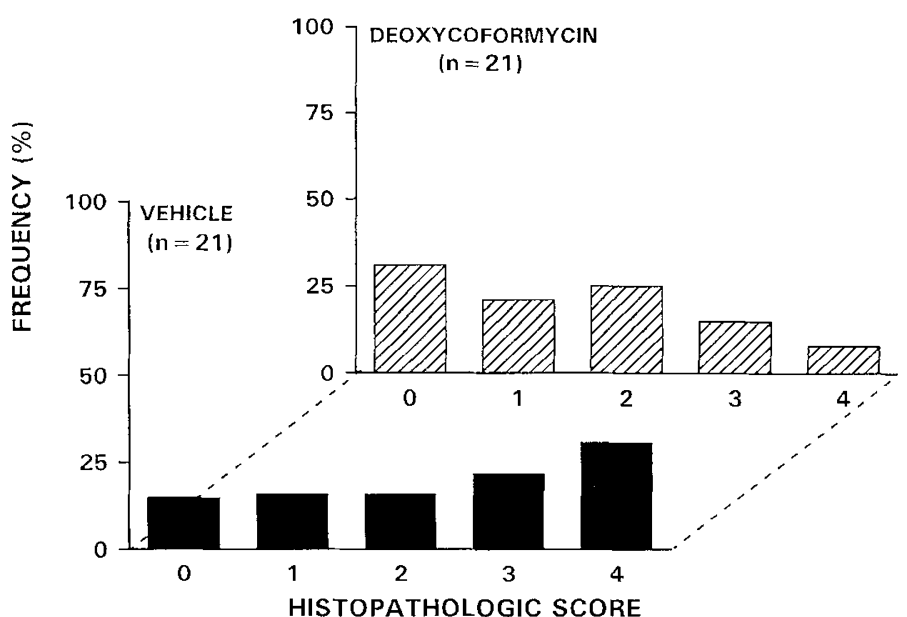

Figure 3. Composite histopathologic results from DCF-treated animals (hatched bars) and their respective vehicle-treated littermates (filled bars) shown as relative frequency distribution histograms of neuronal injury, based on the following semiquantitative scale: $0 \equiv$ no neurons injured; $1 \equiv$ mild injury; $2 \equiv$ moderate injury with some necrotic neurons; $3 \equiv$ severe injury with widespread necrosis; $4 \equiv$ complete infarction. Regional scores in striatum, hippocampal dentate, CA1, CA3, and CA4, thalamus, and cortex (Table 2) were averaged to provide the composite frequency shown for DCF- and vehicle-treated groups. The mean histopathologic injury score for DCF-treated animals $(1.49 \pm 0.11)$ was significantly lower $(p<0.0001$; Mann-Whitney) than that measured in vehicle-treated littermates $(2.39 \pm 0.12)$.

suggest that adenosine-induced reductions in ischemic injury may also derive in part from adenosine's attenuation of free radical production by neutrophils (39) and its augmentation of endogenous antioxidant enzyme activity (40).

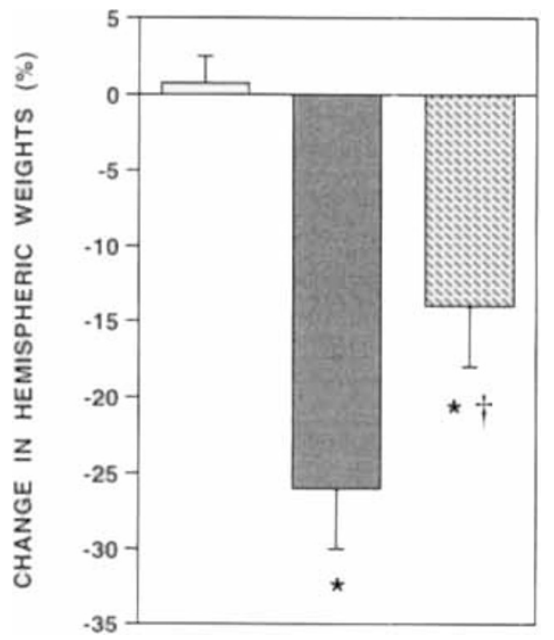

Figure 4. Cerebroprotection by PPF as evidenced by hemispheric weight disparities. The reduction in hemispheric weight in PPF-treated animals $(n=$ 27 ; hatched bar) was $46 \%$ less $(p=0.03)$ than that measured in vehicle-treated littermates ( $n=26$; shaded bar). Changes in nonligated and nonhypoxic controls $\left(n=12\right.$; open bar) are shown. ( ${ }^{*} p<0.05$ vs nonligated, nonhypoxic controls; $\uparrow p<0.05$ vs vehicle-treated animals).

Table 3. Summary of regional histopathologic results for vehicleand PPF-treated animals using a 5-point injury scale (from $0 \equiv$ no injury to $4 \equiv$ total infarction)

\begin{tabular}{lccc}
\hline \multicolumn{1}{c}{ Region $^{a}$} & $\begin{array}{c}\text { Vehicle } \\
(n=13)\end{array}$ & $\begin{array}{c}\text { PPF } \\
(n=14)\end{array}$ & $p$ value \\
\hline Striatum & $3.2 \pm 0.3$ & $2.1 \pm 0.4^{*}$ & 0.024 \\
HPCS-dentate & $2.8 \pm 0.4$ & $2.4 \pm 0.5$ & 0.680 \\
HPCS-CA1 & $3.3 \pm 0.3$ & $2.8 \pm 0.5$ & 0.808 \\
HPCS-CA3 & $3.2 \pm 0.4$ & $2.7 \pm 0.4$ & 0.396 \\
HPCS-CA4 & $2.8 \pm 0.4$ & $2.5 \pm 0.5$ & 0.680 \\
Thalamus & $2.9 \pm 0.4$ & $2.5 \pm 0.4$ & 0.577 \\
Cortex & $3.3 \pm 0.4$ & $2.4 \pm 0.4$ & 0.085
\end{tabular}

${ }^{a}$ HPCS, hippocampus.

${ }^{*} p<0.05 v s$ vehicle-treated littermates (Mann-Whitney test).

These neuroprotective actions depend on a reasonably well developed adenosinergic system in the perinatal brain. That hypoxia and ischemia induce prominent increases in cerebral adenosine levels in several neonatal models (13-16), and $5^{\prime}$-nucleotidase activity has been measured $(10,41)$, indicate that the synthetic enzymes for adenosine production from AMP are developed early. Of particular relevance to the present study is the ontogeny of adenosine deaminase and adenosine 
transporters, which are the respective sites of action for DCF and PPF. Adenosine deaminase activity reaches term levels midway through gestation in guinea pigs (10) and activity in newborn rats is higher than adults (11); adenosine transporters are present in postnatal d 6 rats at adult levels (12) or higher (9). Therefore, the enzyme and transporter responsible for terminating the action of extracellular adenosine are functionally developed in the brain of the newborn and available for pharmacologic inhibition. However, obtaining effects of extracellular adenosine secondary to DCF- and PPF-mediated inhibition of these metabolic pathways requires the subsequent activation of adenosine receptors in several cell types. Studies of the ontogenic profile of the $A_{1}$ adenosine receptor in the rat indicate that, although the receptor is present at birth, adult levels of receptor density are not achieved until at least 3 wk of age $(19,20)$. Furthermore, although receptor affinity does not change with postnatal development $(19,42)$, receptor coupling to $G$ proteins may be weaker in the postnatal period (26). Less information is available regarding the ontogenesis of $\mathrm{A}_{2}$ adenosine receptors, but it has been reported that a similar delay in expression is not observed (42); in fact, the affinity of striatal $\mathrm{A}_{2}$ receptors in postnatal $\mathrm{d} 9$ rats is twice that found in adults (42). Given that cerebroarteriolar smooth muscle relaxation can be demonstrated at birth and earlier $(17,18)$, vascular $A_{2}$ adenosine receptors appear fully developed at term as well. Thus, available evidence suggests that $\mathrm{A}_{2}$ receptor-mediated effects of adenosine, such as inhibition of platelet aggregation, neutrophil-free radical release, astrocytic glycogenolysis, and vasodilation can be realized in the newborn brain in response to potentiation of extracellular adenosine levels. However, these studies also suggest that the extent of glutamate and dopamine release inhibition, hyperpolarization, glucose uptake potentiation, reduction in NMDA-mediated nitric oxide production, and other $A_{1}$ receptor-mediated effects of adenosine may not be as profound in the perinatal period. Given our present finding that adenosine potentiation did afford significant cerebro-protection in this model, we speculate that some of these beneficial $A_{1}$ receptor-mediated actions contributed to the reduction in injury we observed; definitive evidence of these particular actions, however, must await further study.

We attribute the cerebroprotective effects of DCF and PPF in the present study to potentiation of ischemia-induced increases in extracellular adenosine. Considerable in vitro evidence and data from adult animal studies support this contention. Intraperitoneal administration of $1 \mathrm{mg} / \mathrm{kg}$ DCF inhibits brain adenosine deaminase $>98 \%$ (22), and subsequent increases in ischemia-evoked release of adenosine (43) have been documented. When administered preischemically, DCF $(0.5 \mathrm{mg} / \mathrm{kg})$ afforded protection in rat (44) and gerbil (45) cerebral ischemia models. Our study is the first to show a reduction in ischemic injury with DCF when administered after the ischemic insult. By inhibiting the catabolism of adenosine, DCF may also reduce the production of oxygen free radicals via the xanthine oxidase pathway, and conserve adenosine for direct resynthesis of ATP (44).

The cerebroprotective actions of PPF have recently been reviewed (46). The ability of PPF to reduce ischemia-induced glutamate release (47) and increase ischemia-induced extracel- lular adenosine levels secondary to inhibition of adenosine transport has been demonstrated in vitro $(23,48)$ and in vivo (47). Evidence of reduction in hippocampal injury, including the amelioration of calcium influx, neuronal degeneration, and astroglial edema, has been documented in pretreated gerbils $(49,50)$. Our finding of a significant improvement in outcome with postischemic administration is consistent with the reductions in hippocampal injury $(51)$, edema $(52,53)$, and superoxide production (52), and the accelerated energy recovery (53) achieved with similar posttreatment regimens in adult animals. In acute human stroke, PPF posttreatment increased cerebral energy metabolism (54). Additional protective actions of PPF may include a decrease in production of oxygen free radicals by activated microglia (55), and a potentiation of $\mathrm{A}_{2}$ adenosine receptor-mediated actions secondary to phosphodiesterase inhibition (46).

The extent of cerebroprotection we observed with DCF and PPF (34-46\% reduction in injury) was comparable to that we obtained in the same model with a single postischemic dose of MK-801, the noncompetitive NMDA receptor antagonist. Because it is now clear that this prototypical glutamate receptor antagonist exhibits neurotoxic side effects (56), other potential neuroprotective agents for cerebral neuroprotection have garnered more attention. We also demonstrated that protection in our model was not the result of drug-induced hypothermia. Although peripheral administration of adenosine and adenosine agonists can cause hypotension and bradycardia, potentially limiting their clinical usefulness, studies in adult animals indicate that peripheral administration of $0.5 \mathrm{mg} / \mathrm{kg}$ DCF (43), and $2.5 \mathrm{mg} / \mathrm{kg}$ PPF in gerbils (53) to $10 \mathrm{mg} / \mathrm{kg}$ PPF in piglets (our unpublished observations), are without effect on blood pressure. The potential therapeutic utility of DCF and PPF is also underscored by the observations that the potentiation of adenosine action is event- and site-specific $(43,47)$, occurring only where ischemia already evoked an increase in its extracellular concentration.

In summary, significant cerebroprotection was demonstrated in the newborn rat by potentiation of endogenous extracellular adenosine levels. A single postischemic intraperitoneal dose of either the adenosine deaminase inhibitor DCF, or the adenosine transport inhibitor PPF, was neuroprotective in this model. Although adenosine receptor maturation may be incomplete in the newborn brain, augmenting extracellular adenosine levels by DCF and PPF still afforded protection. We conclude that adenosinergic therapy may hold promise for brain protection in infants suffering from asphyxia, cardiac arrest, and other forms of cerebral hypoxia-ischemia.

Acknowledgment. The authors thank Ray Maceren for expert technical assistance.

\section{REFERENCES}

1. Volpe JJ 1995 Hypoxic-ischemic encephalopathy: Clinical aspects. In: Volpe JJ (ed) Neurology of the Newborn. WB Saunders, Philadelphia, pp 314-369

2. Vannucci RC 1992 Perinatal brain metabolism. In: Polin RA, Fox WW (eds) Fetal and Neonatal Physiology. WB Saunders, Philadelphia, pp 1510-1519

3. McDonald JW, Johnston MV 1990 Physiological and pathophysiological roles of excitatory amino acids during central nervous system development. Brain Res Rev $15: 41-70$ 
4. Ferriero DM, Arcavi LJ, Simon RP 1990 Ontogeny of excitotoxic injury to nicotinamide adenine dinucleotide phosphate diaphorase reactive neurons in the neonatal rat striatum. Neuroscience 36:417-424

5. Braun LD, Cornfield EM, Oldendorf WH 1980 Newborn rabbit blood-brain barrier is selectively permeable and differs substantially from the adult. J Neurochem 34:147152

6. Tuor UI 1991 Local cerebral blood flow in the newborn rabbit: An autoradiographic study of changes during development. Pediatr Res 29:517-523

7. Rudolphi KA, Schubert P, Parkinson FE, Fredholm BB 1992 Neuroprotective role of adenosine in cerebral ischaemia. Trends Plarmacol Sci 13:439-445

8. Miller LP, Hsu C 1992 Therapeutic potential for adenosine receptor activation in ischemic brain injury. J Neurotrauma 9 (suppl 2):S563--S577

9. Geiger JD 1987 Adcnosine uptake and $\left[{ }^{3} \mathrm{H}\right]$ nitrobenzylthioinosine binding in developing rat brain. Brain Res 436:265-272

10. Mishra OP, Wagerle LC, Delivoria-Papadopoulos M 1988 5'-Nucleotidase and adenosine deaminase in developing fetal guinea pig brain and the effect of maternal hypoxia. Neurochem Res 13:1055-1060

11. Geiger JD, Nagy JI 1987 Ontogenesis of adenosine deaminase activity in rat brain. J Neurochem 48:147 153

12. Morgan PF, Montgomery P, Marangos PJ 1987 Ontogenetic profile of the adenosine uptake sites in rat forebrain. I Neurochem 49:852-855

13. Park TS, Van Wylen DGL, Rubio R, Berne RM 1987 Increased brain interstitial fluid adenosine concentration during hypoxia in the newborn piglet. J Cereb Blood Flow Metab 7:178-183

14. Kjellmer I, Andiné P, Hagberg H, Thiringer K 1989 Extracellular increase of hypoxanthine and xanthine in the cortex and basal ganglia of fetal lambs during hypoxia-ischemia. Brain Res 478:241-247

15. Aranda JV, Beharry K, Laudignon N, Sasyniuk Bl 1989 Ontogeny of adenosine production and degradation and its implications in neonatal cerebral blood flow regulation. Dev Pharmacol Ther 13:96m103

16. Kim Y-B, Gidday JM, Gonzales ER, Shah AR, Park TS 1994 Effect of hypoglycemia on post-ischemic cortical blood flow, hypercapnic reactivity, and interstitial adenosine concentration. J Neurosurg 81:877-884

17. Kurth CD, Wagerle LC 1992 Cerebrovascular reactivity to adenosine analogues in 0:6-0.7 gestation and near-term fetal sheep. Am J Physiol 262:H1338-H1342

18. Jiang H-X, Chen PC-Y, Sobin SS, Giannotta SL 1992 Age related alterations in the response of the pial arterioles to adenosine in the rat. Mech Ageing Dev 65:257-276

19. Geiger JD, LaBella FS, Nagy JI 1984 Ontogenesis of adenosine receptors in the central nervous system of the rat. Dev Brain Res 13:97-104

20. Marangos PJ, Patel J, Stivers J 1982 Ontogeny of adenosine binding sites in rat forebrain and cerebellum. J Neurochem 39:267-270

21. Rice JE, Vannucci RC, Brierley JB 1981 The influence of immaturity on hypoxicischemic brain damage in the rat. Ann Ncurol 9:131-141

22. Padua R, Geiger JD, Dambock S, Nagy Jl 1990 2'-Deoxycoformycin inhibition of adenosine deaminase in rat brain: In vivo and in vitro analysis of specificity, potency, and enzyme recovery. J Neurochem 54:1169-1178

23. Parkinson FE, Paterson ARP, Young JD, Cass CE 1993 Inhibitory effects of propentofylline on $\left[{ }^{3} \mathrm{H}\right]$ adenosine influx. A study of thrce nucleoside transport systems. Biochem Pharmacol 46:891-896

24. McDonald JW, Roeser NF, Silverstein FS, Johnston MV 1989 Quantitative assessment of ncuroprotection against NMDA-induced brain injury. Exp Neurol 106:289296

25. Towfighi J, Yager JY, Housman C, Vannucci RC 1991 Neuropathology of remote hypoxic-ischemic damage in the immature rat. Acta Neuropathol 81:578-587

26. Morgan PF, Marangos PJ 1987 Ontogenetic appearance of the adenosine receptor precedes N-protein coupling in rat forebrain. Brain Res 432:269--274

27. Burke SP, Nadler JV 1988 Regulation of glutamate and ispartate relcase from sliccs of the hippocampal CAl arca: Effects of adenosine and baclofen. J Neurochem $51: 1541-1551$

28. Miyashita K, Nakajima T, Ishikawa A, Miyatake T 1992 An adenosine uptake blocker, propentofylline, reduces glutamate release in gerbil hippocampus following transient forebrain ischemia. Neurochem Res 17:147--150

29. Choi DW, Rothman SM 1990 The role of glutamate neurotoxicity in hypoxicischemic neuronal death. Annu Rev Neurosci 13:171-182

30. Lupica CR, Cass WA, Zahniser NR, Dunwiddie TV 1990 Effects of the selective adenosine $\mathrm{A}_{2}$ receptor agonist CGS 21680 on in vitro electrophysiology, cAMP formation and dopamine release in rat hippocampus and striatum. J Pharmacol Exp Ther 252:1134-1141

31. Globus MY-T, Ginsberg MD, Dictrich WD, Busto R, Scheinberg P 1987 Substantia nigra lesion protects against ischemic damage in the striatum. Neurosci Lett 80:251 256
32. Greene RW, Haas HL 1991 The electrophysiology of adenosine in the mammalian central nervous system. Prog Neurobiol 36:329-341

33. Bhardwaj A, Northington FJ, Koehler RC, Hanley DF; Traystman RJ 1995 Adenosine $\mathrm{A}_{1}$ receptor stimulation attenuates the $N$-methyl-D-aspartate induced nitric oxide production in the hippocampus: An in vivo microdialysis study. Stroke 26:168(abstr)

34. Hamada $Y$, Hayakawa $T$, Hattori H, Mikawa H 1994 Inhibitor of nitric oxide synthesis reduces hypoxic-ischemic brain damage in the neonatal rat. Pediatr Res $35: 10-14$

35. Gidday JM, Park TS 1992 Effect of 2-chloroadenosine on ccrebrovascular reactivity to hypercapnia in newborn pig. J Cereb Blood Flow Metab 12:656--663

36. Cusack NJ, Hourani SMO $19815^{\prime}$-N-Ethylcarboxamidoadenosine: A potent inhibitor of human platelet aggregation. Br J Pharmacol 72:443-447

37. Magistretti PJ, Hof PR, Martin J-L 1986 Adenosine stimulates glycogenolysis in mouse cerebral cortex: A possible coupling mechanism between neuronal activity and energy metabolism. J Neurosci 6:2558-2562

38. Tominaga K, Shibata S, Watanabe S 1992 A neuroprotective effect of adenosine $A_{1}$-receptor agonists on ischemia-induced decrease in 2-dcoxyglucose uptake in rat hippocampal slices. Neurosci Lett 145:67-70

39. Burkey TH, Webster RO 1993 Adenosine inhibits fMLP-stimulated adherence and superoxide anion generation by human neutrophils at an early step in signal transduction. Biochim Biophys Acta 1175:312m318

40. Maggirwar SB, Dhanraj DN, Somani SM, Ramkumar V 1994 Adenosine acts as an endogenous activator of the cellular antioxidant defense system. Biochem Biophys Res Commun 201:508-515

41. Snyder DS, Zimmerman TR, Farong M, Norton WT, Cammer W 1983 Carbonic anhydrase, $5^{\prime}$-nucleotidase, and $2^{\prime}, 3^{\prime}$-cyclic nuclcotide- $3^{\prime}$-phosphodiesterase activities in oligodendrocytes, astrocytes, and neurons isolated from the brains of developing rats. J Neurochem 40:120-127

42. Sarada N, Reynaud D, Gharib A 1989 S-Adenosylmethionine, S-adenosylhomocysteine and adenosine system. Age-dependent availability in rat brain. Dev Pharmacol Ther 13:104-112

43. Phillis JW, O'Regan MH, Walter GA 1988 Effects of deoxycoformycin on adenosinc, inosine, hypoxanthine, xanthine, and uric acid release from the hypoxemic rat cerebral cortex. J Cereb Blood Flow Metab 8:733-741

44. Lin Y, Phillis JW 1992 Deoxycoformycin and oxypurinol: Protection against focal ischemic brain injury in the rat. Brain Res 571:272-280

45. Phillis JW, O'Regan MH 1989 Deoxycoformycin antagonizes ischemia-induced neuronal degeneration. Brain Res Bull 22:537-540

46. Parkinson FE, Rudolphi KA, Fredholm BB 1994 Propentofylline: A nucleoside transport inhibitor with neuroprotective effects in cerebral ischemia. Gen Pharmacol 25:1053-1058

47. Andiné P, Rudolphi KA, Fredholm BB, Hagberg H 1990 Effect of propentofylline (HWA 285) on extracellular purines and excitatory amino acids in CA1 of rat hippocampus during transient ischaemia. Br J Pharmacol 100:814-818

48. Fredholm BB, Lindström K, Wallman-Johansson A 1994 Propentofylline and other adenosine transport inhibitors increase the efflux of adenosine following electrical or metabolic stimulation of rat hippocampal slices. J Neurochem 62:563-573

49. Dux E, Fastbom J, Ungerstedt U, Rudolphi KA. Fredholm BB 1990 Protective effect of adenosine and a novel xanthine derivative propentofylline on the cell damage after bilateral carotid occlusion in the gerbil hippocampus. Brain Res 516:248-256

50. DeLeo J, Toth L, Schubert P, Rudolphi KA, Kreutzberg GW 1987 Ischemia-induced neuronal cell death, calcium accumulation, and glial response in the hippocampus of the Mongolian gerbil and protection by propentofylline (HWA 285). J Cereb Blood Flow Metab 7:745-751

51. DeLeo J, Schubert P, Kreutzherg GW 1988 Protection against ischemic brain damage using propentofylline in gerbils. Stroke 19:1535-1539

52. Stanimirovic D, Micic DV, Markovic M, Mrsulja BB 1991 Oxidative stress and brain edema: Advantages of multiple drug treatments during early stages of postischemia. J Cereb Blood Flow Mctab 11(suppl 2):S746

53. Sasaki M, Naritomi H, Kanashiro M, Nishimura H, and Sawada T 1989 Effects of propentofylline on energy metabolism of the ischemic brain studied by in vivo ${ }^{31} \mathrm{P}$ nuclear magnetic resonance spectroscopy. Arzeim Forsch 39:886-889

54. Huber M, Kittner B, Hojer C, Fink GR, Neveling M, Heiss W-D 1993 Effect of propentofylline on regional cerebral glucose metabolism in acute ischemic stroke. $J$ Cereb Blood Flow Metab 13:526-530

55. Banati RB, Schubert P, Rothe G, Gehrmann J, Rudolphi K, Valet G, Kreutzberg GW 1994 Modulation of intracellular formation of reactive oxygen intermediates in peritoneal macrophages and microglia/brain macrophages by propentofylline. $\mathbf{J} \mathrm{Cereb}$ Blood Flow Metab 14:145-149

56. Olney JW, Labruycre J, Wang G, Wozniak DF, Price MT, Sesma MA 1991 NMDA antagonist neurotoxicity: Mechanism and prevention. Science 254:1515-1518 